\title{
6
}

\section{Changing Fields of Solidarity in France: A Cross-field Analysis of Migration, Unemployment and Disability}

\section{Manlio Cinalli, Carlo De Nuzzo, and Cecilia Santilli}

\section{Introduction}

The economic crisis that has impacted Europe since 2008 has gone hand in hand with increasing austerity, unemployment and long-term reduction in social benefits and European incomes (Fassin et al. 2013), as well as a dramatic migration crisis across the Mediterranean region (starting with 'Arab Springs' and continuing with the humanitarian catastrophe in Syria). The fact that the migration crisis has grown out of a decade of

M. Cinalli $(\bowtie)$

Department of Social and Political Sciences, University of Milan, Milan, Italy e-mail: manlio.cinalli@unimi.it

C. De Nuzzo

Center of Political Researches (CEVIPOF), Sciences Po, Paris, France e-mail: carlo.denuzzo@sciencespo.fr

C. Santilli

School of Social Work, Lund University, Lund, Sweden e-mail: cecilia.santilli@soch.lu.se 
economic crisis and welfare retrenchment has contributed to weakening established norms of redistribution and solidarity throughout Europe, paving the way for contrasting dynamics. Thus, there has been the development of Eurosceptical, populist and nationalist forces on the one hand (Fekete and Sivanandan 2009), while on the other there has been the emergence of novel forms of solidarity mobilisation within civil society (Kousis et al. 2018). The latter is at the core of this chapter, whose starting point consists of questioning the implications of the economic and migration crises for solidarity organisations in the French context in particular. The main aim is to assess whether solidarity remains nationally bounded or otherwise follows some consistent pattern of transnationalisation for solidarity organisations and, in this case, who are the 'winners' and 'losers' of transnationalisation (Kriesi et al. 2008).

Hence, while this chapter focuses on the specific case of solidarity organisations in France, it does so by giving a transnational twist to the analysis of solidarity organisations. Our treatment considers their characteristics and activities, as well as the main roles and exchanges that they have within and across solidarity fields in France and beyond. The analysis is conducted with reference to the fields of migration, unemployment and disability, spanning public debates and policy-making throughout the last decade in France, Europe and beyond. ${ }^{1}$ Usually, French NGOs are traditionally not transnational and have not yet developed a distinctive transnational character; flourishing since the 1980s onward, solidarity organisations have played a major role in the fight against vulnerability and social exclusion, inscribing their intervention within the space of national politics (d' Halluin 2012; Santilli 2017; Valluy 2008). This is why much of the analysis of this chapter is committed to examining French solidarity organisations in their own national context. Yet it is also dedicated to discussing their transnational developments within the broader context of a full decade of global crises accentuating the growth of solidarity across countries (Lahusen et al. 2018).

\footnotetext{
${ }^{1}$ This analysis derives from Work Package 2 of the TransSOL project, which received funding from the European Union's Horizon 2020 research and innovation programme under grant agreement No. 649435.
} 
In what follows, we compare French solidarity in three fields (migration, unemployment and disability) by assessing endogenous characteristics, organisational activities, as well as roles and exchanges of 30 'transnational solidarity organisations' (henceforth, TSOs). By TSOs, we mean solidarity organisations that are French-based, but may in fact take a number of transnational features in a new context of ongoing global crises and welfare retrenchment (Kousis et al. 2016). Our treatment aims to evaluate how these transnational features relate to endogenous characteristics, activities, roles and networks of our interviewed organisations, affecting their particular experiences within changing fields of solidarity.

Our analysis draws on in-depth qualitative interviews conducted between May and July 2016, following a sampling procedure based on quantitative website-based analysis of TSOs. Beside issue-field variation (ten interviews in each issue-field) and a selection strategy aimed at targeting a relevant number of grassroots groups, ${ }^{2}$ we allowed for geographical variation with 15 TSOs active in Paris and 15 TSOs active in other parts of the country. Furthermore, we allowed for variation in terms of size, internal organisation, membership and strategies of TSOs, thereby including a large variety of organised actors such as politically oriented and service-oriented organisations, formal and informal groups, as well as charities, practical help associations and social movements (see also De Nuzzo and Cinalli 2016).

\section{Facing Crisis and Welfare Retrenchment: Our Theoretical Background}

Since the 1980s, France has started a process of 'rationalisation of welfare' following in the footsteps of emerging 'new monetarist' and 'new right' agendas (Hay 2013, Schmidt and Thatcher 2013). At this time, the end of post-World War II economic growth and expansive social rights pushed for the creation of solidarity organisations caring for vulnerable people against a new course of welfare retrenchment. Institutions and

\footnotetext{
${ }^{2}$ For more information on sampling, see Introduction to this volume and https://blogs.uni-siegen. de/transsol/files/2016/12/Integrated-Report-on-Reflective-Forms-of-Transnational-Solidarity.pdf
} 
policy-makers encouraged these associations to populate the so-called third sector so as to release state institutions from social assistance and reinforcing partnerships between civil society and the state (Laville et al. 2001). Yet, this purpose has also served the objective of constraining the potential recourse to protest actions and contentious politics (Cinalli 2007), an argument to which we shall return in this chapter. Most crucially for our analysis, the increasing call for more civil society since the 1980s has led to the formation of large multi-organisational fields (Curtis and Zurcher 1973), with a growing number of specialised organisations intervening across different fields of solidarity (Cinalli 2004; Giugni and Passy 2001; Massé 2001; Valluy 2008). As we will argue, global crises over the last decade have not changed this long-term trend, but they have nurtured stronger processes of welfare retrenchment and shrinking resources which TSOs must face for their own survival.

Accordingly, we draw on some main scholarly teaching of contentious politics for assessing changing fields of solidarity, including their crosslevel dynamics at the national and transnational levels. Following Resource Mobilisation Theory (Oberschall 1973; McCarthy and Zald 1977), we focus on a number of endogenous characteristics that may have an impact on the way that French TSOs behave at times of crises and retrenchment. Our engagement with endogenous characteristics is quite broad in scope and extends to activities and roles of TSOs in their potential dichotomy between 'politically oriented organisations' engaging in policies on the one hand and, on the other, 'service-oriented organisations' engaging in services directly provided for vulnerable groups themselves (Lelieveldt et al. 2007; Torpe and Ferrer-Fons 2007). These endogenous characteristics of French TSOs account for a first set of more general questions about fields of solidarity. Take, for example, the length of TSO activity in their field: We ask whether the older TSOs stand up better than younger TSOs against welfare retrenchment and global crises. Similar questions will be asked with reference to available resources (are richer TSOs the better placed against retrenchment and crises?), especially the main role played within the solidarity field with regard to the difference between a service-oriented and politically oriented focus. Indeed, previous scholarship has argued that civil society organisations in the solidarity field engage especially in delivering services and advocating 
policy (Baglioni and Giugni 2014), often specialising in either role (Baglioni et al. 2014). Some focus on shorter-term provision of concrete services, while others focus on sensitising the public opinion and influencing policy-making. By drawing on this scholarship, we are endowed with sound analytical tools to detect the subsidiary role that is potentially offered by TSOs in France for complementing welfare provisions, as well as their political role for winning more resources for solidarity.

By considering dynamics of exchanges within fields of solidarity, we then distinguish between mutual contacts among TSOs and their outreach to broader civil society on the one hand and their linking with institutions and policy-makers on the other (Cinalli 2004; Feiock and Scholz 2010; Bassoli and Polizzi 2011). Drawing on previous research that has used relational structures to study the contentious politics in fields of vulnerability and exclusion (Cinalli 2007; Cinalli and Füglister 2008), we focus on the exchanges between TSOs and other actors, thereby moving to a more nuanced study of cross-fields and cross-level interactions. In so doing, the analysis engages with a number of crucial questions about the importance of broader exchanges of transnational solidarity. For example, we ask whether TSOs with a closer access to institutions and policy-makers have more capacity to stand up against retrenchment and crises or, alternatively, whether TSOs can compensate their increasing weakness by establishing broader exchanges allowing for mutual help and co-sharing of resources among solidarity organisations and civil society at large. Most crucially, we can ask whether cross-level networks of solidarity are really an option that is open equally to all TSOs in France or if space for transnationalisation only benefits some winners while at the same time constrains space for losers among the TSOs, thereby serving the purpose of state and policy actors willing to pre-empt contentiousness across fields of solidarity.

Ultimately, our analysis allows for extending the debate over the 'tyranny of structurelessness' (Freeman 1973). Do crises and retrenchment in France reinforce the role and strategies of the best fit among the TSOs, or are crises and retrenchment incapable of stopping new forms of transnationalisation which also revive contributions of the smallest and less resourceful among TSOs? The point is crucial to understand that overall contextual characteristics may not have the same impact on different 
actors within the same field, a hypothesis that is rarely controlled through systematic interaction of exogenous opportunities and endogenous resources. Within the context of a long decade of pre-empting politics (Cinalli 2007), this understanding aims to shed light on what 'the fittest' means today when looking at changing fields of solidarity in France, which TSOs have the best potential to cope with hard times of crises and retrenchment, and hence, what are the long-term perspectives of solidarity in the next future.

\section{Solidarity Fields and the Endogenous Characteristics of TSOs in France}

Our findings show a first crucial element about the way in which crises and retrenchment have impacted on TSOs in France. This is the vicious circle of reduction of their public funding while their beneficiaries are growing in number, making it difficult for TSOs to retain members and personnel just when recruitment of new members and personnel is heavily needed. In our interviews, many representatives of smaller and more informal TSOs (without offices and staff, a more informal status and so forth) have especially complained about the fact that funds are thought especially for service-based activities over emergencies, a key point to which we shall return. It is also interesting to notice that TSOs dealing with migration face the toughest conditions because their intervention is required not only at the same time of crises and retrenchment but precisely when governments and policy-makers give successive restrictive twists to migration policies. The difficulties met in working over solidarity in such a constraining context are exemplary, acknowledged in the words of one interviewee:

The French economic situation was not good and we never had much funding from the state, although this lack of funds was balanced by EU funding. Over the years, however, the situation has become increasingly difficult because the number of migrants needing assistance has increased while staff has remained the same. In addition, we struggle to help migrants gain their rights because of migration policies. (Migr4 07/2016) 
Not surprisingly then, we find that our TSOs have been forced to focus on more urgent needs (for instance, food, housing and health) since the same work must be completed with less manpower, less time and at a faster pace. In the words of one of our interviewees:

One of the consequences of the economic crisis and of the austerity policies is that more and more people in need come seeking our aid. We have to face an increasingly growing demand and we cannot take care of everyone, because we are forced to cut the time for each single person or to filter and try giving priority to the situations we deem to be the most urgent. (Migr8 07/2016)

However, when looking most closely at our sample, we find that the impact of crises and retrenchment varies according to some endogenous characteristics of TSOs and the specific fields within which they are active. Looking at the duration of activities across the TSOs which we interviewed, we find that TSOs which were set up before 2008 face more difficulties than those which were set up afterwards. Many older TSOs complain about the negative impact of the last economic crisis on their work and have perceived a significant contraction of their activities in terms of organisational hardship, lack of funds and decreasing personnel. We also find that the specific solidarity field matters, intersecting with duration of TSOs' activities: Accordingly, we found that, in the field of migration, TSOs are of more recent establishment, in line with the emergency to cope with a truly humanitarian disaster, irrespective of the level of available resources.

In addition, nearly all interviewees are not at their first experience in the solidarity field. The majority of interviewees can be considered to have developed a professional know-how with regard to their specific field of solidarity. Of course, each one has walked their own individual path, but they share common traits in relation to the fact that they have had an average of two jobs and internship or voluntary experiences in various associations before becoming full-time members of their own TSO. Taking the words of a TSO's representative to exemplify: 
I started to take part in my organisation's activities as a volunteer only recently, after retirement, but in truth I have been desiring to work with migrants for a very long time. Before starting my job career as an accountant, I had attended some training courses to prepare for humanitarian aid, only to drop that occupation for personal reasons. That dream, I always carried with me, and here, in this association, I feel like I have a purpose and I'm useful. (Migr2 07/2016)

Emphasis should be put on the fact that the French associative context has been singled out for its gradual professionalism (d' Halluin 2012; Valluy 2008). This process, along with the retrenchment of welfare in this sector, has led to a reduction in militant actors in a shrinking number of smaller and more informal organisations, on the one hand, and, on the other, due to the extensive development of organisations that support the state with their expertise (Santilli 2017). Among the larger number of more strictly organised associations, personal motivation grows together with the increasing professional involvement of individuals. As regards the fewer and more informal groups, a spontaneous and more direct political urge to change the status quo is still alive, responsible for driving members and sympathisers towards activism. This is an obvious contrast with the broader purpose of institutional actors and policy-makers to reduce potential contentiousness across fields of solidarity.

In the field of migration, interviewees speaking on behalf of more formal and larger TSOs show the strongest professionalism, whereby the provision of services is by far dominant compared to protest activities. By contrast, small and informal TSOs still display a strong criticism vis-à-vis the politics of migration as led by French institutions and policy-makers. The situation is similar in the unemployment field, though serviceorientation and political action are not always distinguishable and can be brought together in harmonious terms within the same TSO. In the words of one interviewee:

Our aim is to help people integrate into the world of work and put pressure on the government so that everyone has the same rights and the same job opportunities. There are still people who do not have access to more 
profitable jobs because of their ethnic and social origins; we want to change this situation. (Unemp2 07/2016)

As regards the field of disability, it is again the more formal and larger TSOs that are most strongly committed to improving the concrete situation of their beneficiaries. Thus, some TSOs are made up of disabled volunteers who, in addition to working in the organisation, try to raise public awareness of specific pathologies, while others focus on medical developments for the treatment of different diseases. Whereas the challenge against institutions and policy-makers is not a priority in the field of disability (at least much less than in the fields of migration and unemployment), we do find differences in terms of deeper ideological motivations leading to personal mobilisation. In particular, our interviewees in the field of disability are generally motivated by a very strong interest in fundamental human rights and values, even if only with minor or no reference to current political affairs:

For us, respect, equality and dignity are the most fundamental values. The two main dimensions are subsidiarity and reciprocity. We offer our services for free and we take each person as the actor of his or her own rights. (Disab9 07/2016)

Size and formalisation of interviewed TSOs matter when asking about the specific impact of crises and retrenchment on organisational activities. Smaller and more informal solidarity organisations within our sample were in general the most affected. As discussed, we find that all our TSOs have been forced to focus on more urgent needs and to reduce their political activities. However, while the big and medium-sized TSOs talk especially about the necessity to renounce any further expansion and to readjust their activities in order to balance the provision of services with the advocacy activities, our findings show that smaller and more informal TSOs are often forced to soften their political stance, focusing on the provision of services in order to survive.

Yet, another crucial finding is that this trend helps to maintain balance in the way that TSOs combine their political-based and service-based roles, hence containing the otherwise drastic differentiation in terms of 
the role being played by the larger and more formal TSOs on the one hand and the smaller and more informal TSOs on the other. This is a crucial point which we need to tackle in full in the next section: Both service-orientation and political action coexist within fields of solidarity overall, as well as within individual TSOs as a way to face up to their increasingly constraining milieus.

\section{The Role of TSOs: The Choice Between Services' Provision and Political Engagement}

Scholarly knowledge has looked beyond the impact of crisis per se, arguing that austerity measures, and in particular, the way these measures are implemented within the specific political context of a given country, have in fact the strongest importance (Bermeo and Bartels 2014; Cinalli and Giugni 2013). Most crucially, this scholarly argument claims that austerity fits in a broader long-term political agenda that in many western states has preceded and in fact survived most recent crises (Blyth 2013; Cinalli and Giugni 2016; Schmidt 2016). This specific reading of crises being conveniently used to reinforce a pre-existing neoliberal agenda of welfare cuts and pre-emption of political challenges from below is clearly acknowledged in the words of one interviewee:

The economic crisis has not been as heavily negative as the crisis of the welfare state value. The associations have to supply welfare services provision and this is of course a consequence of the austerity policies, but also a consequence of the redesign of welfare state started some decades ago. I don't think that the economic crisis has changed the structure of the associations. Most of them in France lost their protest and political dimensions some years ago. (Migr3 06/2016)

Accordingly, just as welfare cuts reflect more usual dynamics of power politics at the national level rather than international crisis and external constraints (Pontusson and Raess 2012), in the same way responses by our TSOs are expected to be deeply embedded within their own field and 
the specific policy environment. The specific role of TSOs also stands out in the way they combine service-orientation and political action.

Some interviewees consider their TSOs to be protest, social movement and politically oriented organisations. Yet, the mainly political role of these TSOs is not the same for all: Thus, interviews show that TSOs in the migration and unemployment fields take a stronger political role than TSOs in the disability field. As said, we also observe that political engagement is stronger for smaller and informal associations but weaker for larger and formal TSOs. Larger and medium-sized TSOs have to cope with a contradictory set of roles: They play a crucial role in supplying key services (thereby helping public institutions), while they also maintain a strong critique vis-à-vis institutions and policy-making. Our findings about larger and more formal TSOs show their clear difficulties vis-à-vis crises and retrenchment. State policies have had a negative impact through substantial cuts that push them to appeal further to other private channels for funding. Readjustment has occurred by focusing even further on more urgent needs where state funding is likely to be more available. In the words of an interviewee:

We suffered so much from the crisis that we had to create full-time job positions for some persons dedicated to the search for funds. State and regional funds have visibly shrunk. Now we need some persons to follow every procedure, to do the paper work, to write down projects addressed to private financiers. This situation is so difficult that we are obliged to focus on urgent needs and, sometimes, this means reducing the advocacy activity, at least in our daily practices. (Disab10 07/2016)

Likewise, interviewees speaking on behalf of smaller and more informal TSOs state that their organisation must provide services as an effective way to compensate for decreasing resources. This increasing combination of different roles, such as services' provision and political engagement, is clearly acknowledged by some interviewees as a necessary step to face restrictive twists in the political agenda. In the words of an interviewee: 
In a context where state funds have visibly shrunk, we have to demonstrate that we offer professional services to vulnerable people. We will not have public funding if we say that we want to help irregular migrants, but we will have money if we offer a legal or social support to asylum seekers, for example. In this context, you can't be too militant because in this way you will not have the power to change migration policies. Our strategy is to be professional in order to have public funds. With these funds and with a good reputation, we are able to negotiate with the state. (Migr6 07/2016)

This trend is somewhat obvious in the migration field, where TSOs often intervene by providing services on ad hoc terms, for example, by reacting quickly to a specific situation of emergency. In the words of an interviewee, speaking on behalf of a TSO dealing with the social support and health care for migrants:

Small associations have a hard time proving their worth in a system where funds are progressively cut off and are only granted to organisations following the same efficiency-based logic which inspires capitalist competition. These associations used to do innovative, original things; they cared for integration and for dialogue between French people and migrants. But they didn't make it: Those who try to do something new, don't survive. Only organisations providing services, and which can prove through numbers that they are efficient, survive. (Migr1 07/2016)

However, the same trend favouring a more balanced combination of political and service activities can also be detected in the other two fields of solidarity. In the words of two interviewees speaking on behalf of TSOs mobilising over unemployment and disability, respectively:

We are small associations and it is very difficult for us to prove our efficiency in a system where funds are only granted to organisations based on capitalist competition. It is hard for us to survive. In order to have some money we proposed different services, such as the organisation of professional training for our beneficiaries, or we assist them in the development of networks. These activities allow us to be funded and, of course, to help our beneficiaries. (Unemp9 07/2016) 
After the beginning of the economic crisis, we had no money and our organisation has not received any more public subsidy. And this is happening in a period when public services are dwindling and the needs of sick persons are growing. Hence, I think that our services and our assistance is becoming more and more important. (Disab8 07/2016)

In fact, the increasing combination of services provision and political engagement together is so normal that only one out of the TSOs selfdefining themselves as politically engaged in the field of migration openly attacks the other solidarity organisations for being too focused on services. In the words of its representative:

We act on behalf of migrants; we go find them on the streets and speak with them. We are not offering them any service. We only try to establish a human connection with them, and they in turn begin participating in our activities and helping us. We aren't like other NGOs, too focused on services while lacking in political vision. They said "We are policy-oriented associations", but they have submitted to the national migration policy. (Migr2 07/2016)

In the solidarity field of migration, we find volunteers who search for migrants (stations, roads, etc.), talk with them and try to convince them to get involved in the group's activities. Involved migrants become volunteers themselves, helping in turn even more migrants to learn French and look for places to spend the day or find a regular shelter. Simply put, we observe that different roles (the political-oriented vs. the service-oriented) are by now entwined within practices of solidarity much more than one may otherwise expect (Baglioni et al. 2014). The ultimate evidence consists of a number of interviewees in the migration field who do not define themselves as activists, but rather as 'politically oriented professionals', thereby mixing two roles that have become strongly related with each other within the changing field of solidarity in France. In the words of one interviewee:

We propose services to help the migrants, but at the same time we uphold a clear political position, which is to promote an open and welcoming migration policy. We publish protest documentation against migration 
policies, but we talk and negotiate with governments in order to change things. We are not militant in the strict sense. We are professionals. (Migr7 07/2016)

Also in this case, we find evidence of similar trends in the other two fields of unemployment and disability, respectively. In the field of unemployment, our findings show that protest-oriented associations have come together in a collaborative blog publishing articles and disseminating information about job insecurity. This blog nurtures a broader network of social information and work events, dealing with labour law specifically intended for employees, seniors and the unemployed. We have also found a weekly podcast dedicated to unemployment and the labour market. In addition, the mission of TSOs often underscores the importance of supporting education and training. In the words of an interviewee:

Our aim is to support the education and training of youth from families in precarious situations, for applicants and employment professionals, particularly in Technical Education and Agriculture. (Unemp9 07/2016)

Other TSOs consider themselves to be organisations operating on political-based premises, yet essentially helping institutions and policymakers with the aim of reinforcing the defence of rights of vulnerable parts of the population. In the words of an interviewee:

I do not consider myself a militant who works against the system. The French state has a legal system which grants the same rights to everyone and helps those who need it most. My job is to make this system work as efficiently as possible. For this reason, we work with governments and political parties. (Unemp5 07/2016)

As regards the field of disability, our findings show that solidarity organisations are especially open to a fruitful dialogue across the public and policy domains, furthering the strongest cooperation with institutions and policy-makers. Not surprisingly, this extensive cooperation with institutions and policy-makers means that TSOs in the disability 
field are the least prone to contentious challenges vis-à-vis government and the most inclined to focus above all on the provision of services. Yet some emphasis should be put on TSOs fighting against HIV. While becoming less militant over time, these TSOs stand out for their longterm political engagement in the solidarity field. ${ }^{3}$

Looking at the three fields, the expansion of service-based activities is not an obstacle to TSOs' solidarity. In fact, solidarity seems to be a value of the majority of our TSOs, sometimes in open distinction vis-à-vis other humanitarian or charity organisations. In the words of an interviewee:

We define our organisation as a solidarity organisation because we don't agree with the humanitarian approach or with charity organisation. At the beginning, we were a humanitarian organisation but we understood the importance of an equal relationship with our beneficiaries. We support them, both by the provision of services and by acting politically in order to defend their rights. Solidarity means being part of a human community and defending the rights of vulnerable people. (Migr1 07/2016)

A similar vision can also be detected in the words of another interviewee speaking on behalf of a TSO mobilising over disability:

I think that our answer to the growth of vulnerable people, at least our objective, is solidarity. Of course, we do this by helping our beneficiaries with different activities that are service-based. These services should be provided by public institutions but actually this is not the case. (Disab8 07/2016)

The words of these two interviewees show two different aspects. On the one hand, we see the strong importance of solidarity in the actions of our TSOs. On the other hand, we also see that TSOs adopt a more practical approach whereby service and advocacy activities can be combined together.

\footnotetext{
${ }^{3}$ When the HIV epidemic spread to France in the 1990s, anti-HIV associations were involved in defending the rights of those suffering from the disease, contributing crucially to the implementation of health system reforms in 1998 (Santilli 2017).
} 


\section{Networks and Cross-level Dynamics}

Moving on to the analysis of interactions among TSOs and with other actors in their own fields of solidarity, our findings show that TSOs have fostered mutual contacts among themselves, with broader civil society, as well as with government and policy-makers. Not surprisingly, the problem of funding is extensively acknowledged. Mutual contacts and help among TSOs are indeed considered to be a first important step to survive hard times and impoverished resources. Mutual interactions seem an obvious step for organising larger events and activities, but a broader civil society outreach is also essential. For example, information is exchanged among TSOs, universities, research centres, and media outlets and then made available for the general public in order to increase awareness of solidarity issues through an intense activity of publications and dissemination. Six of the interviewees, for example, have singled out their collection of data on specific problems that vulnerable people face when trying to gain access to basic welfare provisions.

This first type of connection among TSOs working together and a broader civil society outreach is not in opposition, but it often leads to furthering contact with institutions and policy-makers. Of course, the relationship between TSOs and their institutional counterparts within fields of solidarity can always be tense, even when referring to the least contentious field of disability, owing to the reduction of public funds and restrictive policies. In the words of an interviewee:

During the last year, we have not received public funds either at the national level or at the regional level and the relationship with the government has become tenser. (Disab9 10/2016)

However, the linking with institutions and policy-makers is seen as a viable route to increase the visibility of TSOs, as well as their capacity to face reduction of funding and political choices by government at times of crises. While nurturing links with policy actors in their own field at the national level, TSOs also communicate extensively with regional authorities, as well as with departments and town halls, all standing up as potential sources for funding at the subnational level. Most crucially, interactions 
with institutions and policy-makers extend at the supranational level, owing to the growing contact between TSOs and European policy-makers.

This seems to indicate that the specific aspect of 'transnational solidarity' is somewhat weak when dealing with cross-level interactions forged by French TSOs. The latter try to seize supranational political opportunities in a tactical and utilitarian fashion, with the main aim to impact on European policies, as well as gaining further funding opportunities that may compensate for weak leverage on policy-making and funding reduction at the national and subnational levels. In fact, the tactical and utilitarian dimension can be referred to as a somewhat thinner type of Europeanisation by which TSOs appeal to Europe in an 'externalising' fashion (Chabanet 1998; Balme and Chabanet 2008) through which the real stakes remain at the national level.

The strategic and utilitarian logic seems to prevail also when TSOs shape their mutual contacts among themselves within their own field of solidarity. In the words of an interviewee:

The EU gives loads of funding to big organisations and NGOs, but they also fund smaller associations, mainly if they are part of a national or international network. (Migr8 06/2016)

This finding may indicate the potentially regressive dynamics with reference to the operation of broader networks involving many TSOs working in fields of solidarity at the subnational, the national and the European levels (della Porta and Caiani 2007; Lahusen, 2004). ${ }^{4}$

At the same time, emphasis should be put on the fact that the largest and most formal TSOs are those that engage the most with transnational solidarity practices. They share lobbying practices, gain more legitimacy and a louder voice transnationally, cooperate mainly in transnational solidarity support, raise transnational awareness and

\footnotetext{
${ }^{4}$ For example, a group network was created by many organisations and some of them, by 2007 , decided to focus their action on inequality in France. After 2007, this group organised more meetings with the actors of solidarity at the national and European levels. Through this broad cooperation among French TSOs and other solidarity organisations in other European countries, a higher number of development funds was obtained (De Nuzzo and Cinalli 2016).
} 
organise transnational political events and campaigns. An interesting example is the development of a Mediterranean network whereby many TSOs (not just those related to migration) have set up agencies abroad, such as in Tunisia, Morocco and Algeria:

We can say that after the crisis we have increased our international activities. Maybe it's a question of funding but actually we have always been interested in these kinds of linkages. Maybe the crisis has been an opportunity. (Disab5 07/2016)

Yet, for the medium-sized and smaller TSOs of our sample, it seems more difficult to engage in cross-national activities, unless they are part of an umbrella organisation or network. Our findings show that these organisations organise congresses and conferences in France or in other countries where they discuss various national and transnational resolutions. However, while our TSOs see this as an important type of activity, they also state that the development of more stable transnational actions remains very difficult. In the words of an interviewee:

Unfortunately, we have no time for building important and structured transnational actions. For example, here (in France) we have the problem of migrants, asylum seekers who arrive in Italy and then came here. And then, they have to go back to Italy. Now, collaboration with Italian associations to help these people and change the situation would be useful. We have organised some meetings, we have some contacts but not a real political transnational network. (Migr2 07/2016)

Transnational communication and actions obviously remain a suitable route to walk for any funding occasion, especially by the bigger and more structured TSOs that have more resources. Otherwise, due to the costly transnational exchanges, our TSOs remain primarily active at the subnational and national levels. In the words of an interviewee:

One of the first survival strategies to change the public policies in this country is to collaborate with similar associations, also with bigger and more structured organisations, working at the national level. In this way, 
we might have economic support to continue our work but we can also change the political context. (Migr4 09/2016)

\section{Conclusions}

This chapter has focused on the dynamics of solidarity in the fields of migration, unemployment and disability, at times of economic crisis and welfare retrenchment in France. Among the various findings, there are three points that deserve major attention. First, we have put a strong emphasis on the changing role of TSOs in the way they combine political and service activities. While it is stronger in some field than others, the main trend consists of service-orientation and political action being progressively interwoven together. We have shown the increasing role of less resourceful TSOs as service providers, allowing for access to public funding within an increasingly constraining context (even if this does not mean giving up the critique towards institutions and policy-makers). This trend, however, is in more general terms observable for the majority of our TSOs, thus contributing to the explanation of the overall reduction in militant action and protests.

Yet changing combinations do not proceed necessarily by increasing substitution of political activities with service provision. Our main argument has been that TSOs mobilising over solidarity in France stand out due to their capacity to adjust flexibly according to different conditions. We have put a strong emphasis on the notion of 'politically oriented professionals'-emerging with force in the narrative of interviewees-providing clear evidence that flexibility between policy-oriented and service-oriented activities has been interiorised in full by the TSOs themselves. We thus expect that TSOs could become more politicised in the future, should the economic and political conditions change once again.

The second point is about networks. We have shown that our TSOs aim to engage with solidarity through the development of mutual contacts, further contacts with broader civil society, as well as via links with policy-makers and institutions. Hence, their effort to ground solidarity into concrete contacts explains why the most extensive networks are forged at the national and the subnational level. Since closer contacts 
among TSOs are crucial to survive hard times of economic crisis and welfare retrenchment, it was not surprising to find that the majority of our TSOs have intensified connections with other neighbouring actors in the same field. As regards more distant transnational contacts, we have found that they are especially forged in residual terms, merely as a tactic and utilitarian means of 'externalisation' in order to increase funding rather than nurturing solidarity.

What is more, our findings show that the larger and more structured TSOs also have an advantage in terms of transnationalisation. Their richer resources enable them to develop transnational networks in order to gain further funding and more influence. By arguing that cross-level networks of solidarity are an option that is not open equal among our TSOs, we have moved on to discuss our final point. In this case, we have put a strong emphasis on the potential advantage of the most structured organisations - which we can term 'the fittest' - within solidarity fields in France. Among the interviewed TSOs, the most structured ones have more resources and a better capacity to stand up to restricting conditions. We have argued that the strategy of the fittest is two-fold. On the one hand, the most structured TSOs, just like many others, focus on more urgent needs, for which state funding is more readily available. On the other hand, they also appeal to private channels for funding, but in so doing, they rely on resources that are not available for smaller organisations. Ultimately, our findings show that the smallest and more informal solidarity organisations are the most affected by crisis and retrenchment, turning to increasing provision of services at least until new conditions allow for reviving their political stance. Taken from this viewpoint, the economic crisis and welfare retrenchment in France have served to preempt potential challenges of solidarity movements.

\section{References}

Baglioni, S., \& Giugni, M. (Eds.). (2014). Civil Society Organizations, Unemployment, and Precarity in Europe. Houndmills, Basingstoke: Palgrave Macmillan. 
Baglioni, S., Lorenzini, J., \& Mosca, L. (2014). Civil Society Organizations, Unemployment, and Precarity in Europe: Between Service and Policy. In S. Baglioni \& M. Giugni (Eds.), Civil Society Organizations, Unemployment, and Precarity in Europe (pp. 13-31). Houndmills, Basingstoke: Palgrave Macmillan.

Balme, R., \& Chabanet, D. (2008). European Governance and Democracy: Power and Protest in the EU. Lanham: Rowman and Littlefield.

Bassoli, M., \& Polizzi, E. (Eds.). (2011). La governance dei territori. Partecipazione e rappresentanza della società civile nelle politiche locali. Milano: Angeli.

Bermeo, N., \& Bartels, L. M. (Eds.). (2014). Mass Politics in Tough Times: Opinions, Votes and Protest in the Great Recession. Oxford: Oxford University Press.

Blyth, M. (2013). Austerity. Oxford: Oxford University Press.

Chabanet, D. (1998). L'engagement comme mise en jeu de la personne. Revue française de science politique, 48(2), 306-310.

Cinalli, M. (2004). Horizontal Networks vs. Vertical Networks in MultiOrganisational Alliances: A Comparative Study of the Unemployment and Asylum Issue-Fields in Britain. EurPolCom Working Papers 8: 1-25. Leeds: University of Leeds.

Cinalli, M. (2007). Between Horizontal Bridging and Vertical Governance: Probeneficiary Movements in New Labour Britain. In D. Purdue (Ed.), Civil Societies and Social Movements: Potentials and Problems (pp. 88-108). London: Routledge.

Cinalli, M., \& Füglister, K. (2008). Networks and Political Contention Over Unemployment: A Comparison of Britain, Germany and Switzerland. Mobilization, 13, 259-276.

Cinalli, M., \& Giugni, M. (2013). Political Opportunities, Citizenship Models and Political Claim-Making Over Islam. Ethnicities, 13(2), 147-164.

Cinalli, M., \& Giugni, M. (2016). Collective Responses to the Economic Crisis in the Public Domain: Myth or Reality. Politics and Policy, 44, 427-446.

Curtis, R. L., \& Zurcher, A. L. (1973). Stable Resources of Protest Movements: The Multi-Organizational Field. Social Forces, 52, 53-61.

de Nuzzo, C., \& Cinalli, M. (2016). France. In TransSOL (Ed.), Work Package 2 Integrated Report on Reflective Forms of Transnational Solidarity (pp. 147-160). Retrieved from https://blogs.uni-siegen.de/transsol/files/2016/12/IntegratedReport-on-Reflective-Forms-of-Transnational-Solidarity.pdf 
della Porta, D., \& Caiani, M. (2007). Europeanization from Below? Social Movements and Europe. Mobilization: An International Quarterly, 12(1), 1-20.

Fassin, D., Eideliman, J.-S., Coutant, I., Bouagga, Y., Fernandez, F., Fischer, N., Kobelinsky, C., Makaremi, C., Mazouz, S., \& Roux, S. (2013). Juger, réprimer, accompagner. Essai sur la morale de l'État. Paris: Le Seuil.

Feiock, R. C., \& Scholz, J. T. (Eds.). (2010). Self-Organizing Federalism: Collaborative Mechanisms to Mitigate Institutional Collective Action Dilemmas.

New York: Cambridge University Press.

Fekete, L., \& Sivanandan, A. (2009). A Suitable Enemy: Racism, Migration and Islamophobia in Europe. London: Pluto Press.

Freeman, J. (1973). The Tyranny of Structurelessness. Berkeley Journal of Sociology, 17, 151-164.

Giugni, M., \& Passy, F. (Eds.). (2001). Political Altruism? Solidarity Movements in International Perspective. Lanham: Rowman \& Littlefield Publishers.

Halluin, d.' E. (2012). Les épreuves de l'asile. Paris: éditions EHESS.

Hay, C. (2013). Treating the Symptom Not the Condition: Crisis Definition, Deficit Reduction and the Search for a New British Growth Model. The British Journal of Politics and International Relations, 15(1), 23-37.

Kousis, M., C. Lahusen, \& A. Loukakis (2016). Transnational Solidarity Organisation Analysis. In: TransSOL (ed.), Work Package 2 Integrated Report on Reflective Forms of Transnational Solidarity (pp. 21-74). Retrieved from https://blogs.uni-siegen.de/transsol/files/2016/12/Integrated-Report-onReflective-Forms-of-Transnational-Solidarity.pdf

Kousis, M., Giugni, M., \& Lahusen, C. (2018). Action Organization Analysis: Extending Protest Event Analysis Using Websites. American Behavioral Scientist, 62(6), 739-757.

Kriesi, H., Grande, E., Lachat, R., Dolezal, M., Bornschier, S., \& Frey, T. (2008). West European Politics in the Age of Globalization. Cambridge: Cambridge University Press.

Lahusen, C. (2004). Joining the Cocktail-Circuit. Social Movement Organizations at the European Union. Mobilization: An International Quarterly, 9(1), 55-71.

Lahusen, C., Kousis, M., Zschache, U., \& Loukakis, A. (2018). European Solidarity in Times of Crisis: Comparing Transnational Activism of Civic Organisations in Germany and Greece. Österreichische Zeitschrift für Soziologie, 43(Suppl 1), 173-197. 
Laville, J.-L., Caillé, A., Chanial, P., Dacheux, E., Eme, B., \& Latouche, S. (2001). Association, démocratie et société civile. Paris: Éditons La Découverte, Mauss et Crida.

Lelieveldt, H., Astudillo, J., \& Stevenson, L. (2007). The Spectrum of Associational Activities: From Self-Help to Lobbying. In W. Maloney \& S. Rossteutcher (Eds.), Social Capital and Associations in European Democracies (pp. 81-95). London: Routledge.

Massé, J.-P. (2001). Genèse et institutionnalisation du dispositif d'accueil des réfugiés politiques en France. Cahiers de la sécurité intérieure, 45, 45-68.

McCarthy, J. D., \& Zald, M. N. (1977). Resource Mobilization and Social Movements: A Partial Theory. American Journal of Sociology, 82, 1212-1241.

Oberschall, A. (1973). Social Conflict and Social Movements. Englewood Cliffs: Prentice-Hall.

Pontusson, J., \& Raess, D. (2012). How (and Why) Is This Time Different? The Politics of Economic Crisis in Western Europe and the United States. Annual Review of Political Science, 15(1), 13-33.

Santilli, C. (2017). Accès aux soins et Politiques migratoires en Europe. Le parcours de vie des migrants subsahariens vivant avec le VIH et l'hépatite b. Un regard croisé entre la France et l'Italie. PhD dissertation, Aix-Marseille University.

Schmidt, V. A. (2016). Reinterpreting the Rules 'by Stealth' in Times of Crisis: A Discursive Institutionalist Analysis of the European Central Bank and the European Commission. West European Politics, 39(5), 1032-1052.

Schmidt, V. A., \& Thatcher, M. (2013). Resilient Liberalism in Europe's Political Economy. Cambridge: Cambridge University Press.

Torpe, L., \& Ferrer-Fons, M. (2007). The Internal Structure of Associations. In W. Maloney \& S. Rossteutcher (Eds.), Social Capital and Associations in European Democracies (pp. 81-95). London: Routledge.

Valluy, J. (2008). Sociologie politique de l'accueil et du rejet des exilés. Strasbourg: HDR diss. University Robert Schumann. 
Open Access This chapter is licensed under the terms of the Creative Commons Attribution 4.0 International License (http://creativecommons.org/licenses/ by/4.0/), which permits use, sharing, adaptation, distribution and reproduction in any medium or format, as long as you give appropriate credit to the original author(s) and the source, provide a link to the Creative Commons licence and indicate if changes were made.

The images or other third party material in this chapter are included in the chapter's Creative Commons licence, unless indicated otherwise in a credit line to the material. If material is not included in the chapter's Creative Commons licence and your intended use is not permitted by statutory regulation or exceeds the permitted use, you will need to obtain permission directly from the copyright holder.

(c) (i) 